\title{
AMMI Model for Yield Stability Analysis of Linseed Genotypes for the Highlands of Bale, Ethiopia
}

\author{
Tadele Tadesse*, Amanuel Tekalign, Gashaw Sefera, Behailu Muligeta
}

Oromia Agriculture Research Institute, Sinana Agriculture Research Center, Bale-Robe, Ethiopia

Email address:

tadyeko20@gmail.com (T. Tadesse), tadeleta20@yahoo.com (T. Tadesse)

${ }^{*}$ Corresponding author

To cite this article:

Tadele Tadesse, Amanuel Tekalign, Gashaw Sefera, Behailu Muligeta. AMMI Model for Yield Stability Analysis of Linseed Genotypes for the Highlands of Bale, Ethiopia. Plant. Vol. 5, No. 6, 2017, pp. 93-98. doi: 10.11648/j.plant.20170506.12

Received: October 11, 2017; Accepted: October 25, 2017; Published: December 7, 2017

\begin{abstract}
In order to determine stable linseed genotypes with high grain yield, field experiments were conducted with 14 genotypes for two years (2014-2015) at three locations in the highlands of Bale zone, Ethiopia. The genotypes were laid out in randomized complete design with four replications in each environment. The objective of this study was to identify and recommend high yielder, stable genotypes for testing sites and similar agro-ecologies using the stability parameters. The combined analysis of variance showed highly significant differences for the genotypes, environment, and genotype by environment interaction indicating the possible existence of stable genotypes among the tested once. The results of AMMI (additive main effect and multiplicative interaction) analysis indicated that the first two AMMI (AMMI1-AMMI2) were highly significant $(\mathrm{P}<0.01)$. The partitioning of the total sum of square exhibited that the effect of environment was a predominant source of variation followed by genotypes and GE interaction effect. Based on the stability parameters regression coefficient, deviation from regression and mean grain yield out of the tested G6, G9, G11, and G8 were found to be stable. However, the AMMI Stability Value (ASV) discriminated genotypes G12, G4, G6, G13, and G9 as stable genotypes respectively. Based on the Genotypes Selection Index (GSI) the most stable genotypes with high grain yield were G6 and G9. Therefore these two genotypes were identified as candidate genotypes to be verified for possible release.
\end{abstract}

Keywords: AMMI, ASV, Stability, GSI

\section{Introduction}

Ethiopia is considered to be the center of diversity for linseed [25]. The principal linseed growing regions in Ethiopia are located at altitudes between 1800 and $2800 \mathrm{~m}$, although it occasionally grows at altitudes as low as $1680 \mathrm{~m}$ or as high as 3430m [4]. Arsi, Bale, Chercher Mountains, Eastern Welega, Eastern Gojam, Tigray, and southeast Welo, and Shewa are the major areas of production where frost is a problem for other oilseed crops such as noug (Guizotia abyssiniccacass) and Ethiopian mustard (Brassica carinata A. Braun). Linseed is a major oilseed and rotation crop for barley in higher elevations of Arsi, Bale, Gojam, Gonder, Wello, Shewa and Welega parts of Ethiopia. High yields of wheat, barley and tef can be obtained following linseed [11]. Though the crop has so many important merits, its production per unit areas is very low due to the lack of stable and high yielding cultivar. Therefore, improving yield and yield stability is the main objectives of linseed breeding program in the country. Yield is a complex character where it is highly influenced by both genes as well as environment.

Adaptation is the result of genotypes $\mathrm{x}$ environment interaction and generally falls in to two classes: 1) the ability to perform at an acceptable level in a range of environment, general adaptability 2) the ability to perform well in desirable environments, specific adaptability [7, 21]. The genotypeenvironment interaction reduces association between phenotypic and genotypic values leads to bias in the estimates of gene effect combining ability for various characters sensitive to environmental fluctuations. Such traits are less preferable to selection [5]. The existence of genotype-environment interaction (GEI) complicates the identification of superior genotypes for a range of environments and calls for the evaluation genotypes in many environments to determine their true genetic potential [24]. 
The importance of $\mathrm{G} \times \mathrm{E}$ interactions in cultivar evaluation and breeding programs has been demonstrated almost in all crops. Various statistical methods (parametric and nonparametric) have been proposed to study genotype environment interaction [1-2, 13-15 and 17-18]. To identify linseed genotypes with wider or specific adaptation to different environments, multi-location yield trial are grown each year. These have lead to empirical identification of superior cultivars, sum of which have been released in several countries. Multi-location yield trials facilitate quantification of the environment and the GEI effects. However, a fact not generally recognized is that, in addition, every yield trial by analyzing processes that determine yield can inexpensively quantify the genetic, physiological and environmental controls that results in yield differences among cultivars, seasons and locations [22]. Various methods of GE interaction analysis exist, including parametric and non-parametric approaches.

The most widely used parametric methods is the joint regression including regression coefficient (bi) variance of deviation from regression $\left(\mathrm{S}^{2} \mathrm{di}\right)$ [7 and 19].

The ordinary form of Analysis of variance (ANOVA) is an additive model and therefore describes only the main effect. Principal component analysis is a multiplicative model and has the opposite problem of not describing the additive main effects. Linear regression models combine the additive and multiplicative components and thus analyze both main effects and interaction, but in general they confound the interaction with the main effects reducing its power for general significance testing [7].

The additive main effects and multiplicative interaction (AMMI) model is a powerful multivariate method to multienvironmental trial. This technique incorporates both additive and multiplicative components into an integrated, powerful least square analysis $[6,16$, and 19]. Therefore the objective of the present study proposed to identify stable and high yielding genotypes for possible releases.

\section{Materials and Methods}

\subsection{Testing Sites al Locations}

The experiment was carried out at three locations. One of the experiments was conducted at the research farm of Sinana Agricultural Research Center, Oromia Agriculture Research Institute, Sinana, and the other two were at a site in the farmer's field representing for linseed production. The experiment was conducted at each location on vertisol clay loam soil under rain fed conditions during the meher season (August-January) of 2014/15 and 2015/16 cropping season. Sinana Research Center $\left(7^{\circ} \mathrm{N}\right.$ latitude and $40^{\circ} \mathrm{E}$ longitude; and $2400 \mathrm{~m}$ a.s.1.) is located $463 \mathrm{~km}$ south east of Addis Ababa and East of Robe, the capital of Bale zone. The other two locations are located (Agarfa) 45-km and (Adaba) $70 \mathrm{~km}$ from Sinana in the Southwest direction. Because of the suitability of the region for linseed production, it is expected that the test genotypes would express their genetic potential to a higher extent for the traits under consideration.

Fourteen linseed genotypes (Table 1) were tested In order to determine their stability across the testing sites for two years (2014-2015) at three locations (Sinana, Agarfa and Adaba) representing the highlands of bale zone, south eastern Ethiopia. The experimental layout at each environment was complete randomized block design with four replications. The experimental plot size was $4.8 \mathrm{~m}^{2}$ (6 rows at $20 \mathrm{~cm}$ apart and $4 \mathrm{~m}$ long). The four central rows were used for data collection. Combined analysis of variance using balanced ANOVA was computed using CROPSTAT program. The additive main effect and multiplicative interaction (AMMI) analysis was performed using the model suggested by [3] as:

$$
\mathrm{Y}_{\mathrm{ij}}=\mu+\mathrm{g}_{\mathrm{i}}+\mathrm{e}_{\mathrm{j}}+\sum_{\mathrm{n}=1}{ }^{\mathrm{h}} \lambda_{\mathrm{n}} \alpha_{\mathrm{ni}} \cdot \mathrm{Y}_{\mathrm{nj}}+\mathrm{R}_{\mathrm{ij}} \text { where, }
$$

$Y_{i j}$ is the yield of the ith genotype in the jth environment, $\mu$ is the grand mean, $g_{i}$ is the mean of the ith genotype minus the grand mean $e_{j}$ is the mean of $j$ th environment minus the grand mean, $\lambda_{n}$ is the square root of the eigen value of the principal component Analysis (PCA) axis, $\alpha_{n i}$ and $Y_{n j}$ are the principal are the principal component scores for the PCA axis $\mathrm{n}$ of the ith genotype and jth environment, respectively and $R_{i j}$ is the residual. The GE biplot was projected for the 14 genotypes tested at 6 environments. The regression of yield for each variety on yield means for each environment was computed and parameters MS-REG, the contribution of each variety to the regression component of the treatment $x$ location interaction and MS-TL the contribution of each variety to interaction MS, were estimated with the Crop Stat program.

\subsection{AMMI Stability Value (ASV)}

The ASV is the distance from the coordinate point to the origin in a two dimensional of IPCA1 score against IPCA2 scores in the AMMI model [20]. Because of the IPCA1 score contributes more to the GE interaction sum of square, a weighted value is needed. This weight is calculated for each genotypes and environment according to the relative contribution of IPCA1 to IPCA2 to the interaction SS as follows,

$$
\mathrm{ASV}=\sqrt{\left[\frac{\text { SSIPCA1 }}{\text { SSIPCA2 }(I P C A 1 \text { score })]^{2}+\lceil I P C A 2\rceil^{2}}\right.}
$$

Where, $\frac{S S I P C A 1}{S S I P C A 2}$ is the weight given to the IPCA1 value by dividing the IPCA1 sum squares by the IPCA2 sum of squares. The larger the IPCA score, either negative or positive, the more specifically adapted a genotype is to certain environments. Smaller IPCA score indicate a more stable genotype across environment.

\subsection{Genotype Selection Index (GSI)}

Based on the rank of mean grain yield of genotypes $\left(\mathrm{RY}_{\mathrm{i}}\right)$ across environments and rank of AMMI Stability Value $\left(\mathrm{RASV}_{\mathrm{i}}\right)$ a selection index GSI was calculated for each genotype which incorporate both mean grain yield and 
stability index in a single criteria $\left(\mathrm{GSI}_{\mathrm{i}}\right)$ as

$$
\mathrm{GSI}_{\mathrm{i}}=\mathrm{RY}_{\mathrm{i}}+\mathrm{RASV}_{\mathrm{i}}
$$

Table 1. Genotype code and the name of 14 linseed genotypes.

\begin{tabular}{lll}
\hline No. & Genotype code & Name \\
\hline 1 & G1 & CDC 1747 X CI-1652/SPS2 \\
2 & G2 & CDC 1747 X CI-1652/SPS1 \\
3 & G3 & CHILALO X R12-D33C/SPS3 \\
4 & G4 & CHILALO X R12-D33C/SPS8 \\
5 & G5 & CI-1652 X CDC 1747/SPS1 \\
6 & G6 & CHILALO X R12-N27G/SPS6 \\
7 & G7 & CHILALO X R12-N27G/SPS11 \\
8 & G8 & CI-1652 X R12 -D33C/SPS6 \\
9 & G9 & R12-N100 X CI-1525/SPS4 \\
10 & G10 & R12-N100 X CI1525/SPS7 \\
11 & G11 & R12-N100 X CI1525/SPS10 \\
12 & G12 & Dibanne \\
13 & G13 & Jitu \\
14 & G14 & Local \\
\hline
\end{tabular}

\section{Result and Discussion}

The result of combined analysis of variance (Table 2) showed high significant differences for genotypes, environment and GE interaction indicating the effect of environment in the GE interaction, genetic variability and possibility of selection for stable genotypes. As it is indicated by different scientists, [6-7] when GE interaction was significant, it is possible to proceed and calculate the stability for the tested genotypes. Mean comparison for the tested genotypes indicated that maximum grain yield was obtained from G6 (1.85t/ha) followed by G9 (1.69t/ha) and G11 $(1.64 \mathrm{t} / \mathrm{ha})$ whereas the least mean grain yield was obtained from G3 (1.42t/ha).

Table 2. Combined analysis of variance for grain yield of linseed at three locations over two years.

\begin{tabular}{lll}
\hline Source of Variation & Degree of freedom & Mean Square \\
\hline Year (Y) & 1 & $3.55262^{* *}$ \\
Location(L) & 2 & $8.929441^{* *}$ \\
Replication & 3 & $0.509109 * *$ \\
Genotype $(G)$ & 13 & $0.281792^{* *}$ \\
Y x L & 2 & $3.07369^{* *}$ \\
Y x G & 13 & $0.103805^{* *}$ \\
Lx G & 26 & $0.099389^{* *}$ \\
Y x L X G & 26 & $0.055773^{*}$ \\
RESIDUAL & 249 & $0.061127 * *$ \\
CV\% & & 15.7 \\
\hline
\end{tabular}

** Significant at $1 \%$ of probability level

The result of regression analysis (Table 3 ) revealed that the main effects of genotypes and GE interaction were relatively small and accounted $10.01 \%$ and $14.71 \%$ of the total sum of square (TSS), respectively. Liner GE interaction was not significant and accounted for $18.72 \%$ of the variability in the GE interaction.

As a general rule the effectiveness of regression analysis is when $50 \%$ of the total sum squares is accounted for by liner GE interaction [12], hence regression analysis is not useful for stability analysis of genotypes [23].
Table 3. Regression analysis of stability for linseed genotypes.

\begin{tabular}{lllll}
\hline Source of variation & D. F. & S. S. & M. S. F & TSS (\%) \\
\hline Genotypes (G) & 13 & 0.915823 & $0.070448^{* *}$ & 10.01 \\
Location (L) & 5 & 6.88972 & $1.37794^{* *}$ & 75.29 \\
G X L & 65 & 1.34592 & $0.020706^{* *}$ & 14.71 \\
G X Site Reg & 13 & 0.251952 & 0.019381 & 18.72 \\
Deviation & 52 & 1.09396 & $0.021038^{* *}$ & 81.28 \\
TOTAL & 83 & 9.15146 & & \\
\hline
\end{tabular}

** Significant at $1 \%$ of probability level

AMMI model analysis: in AMMI model, principal component analysis is based on the matrix of deviation from additivity or residual will be analyzed. In this respect both the results of AMMI analysis, the genotypes and environment will be grouped based on their similar responses [9, 19, and 23]. Using ANOVA yield sum of square was partitioned into genotype, environment, and GE interaction. GE interaction was further portioned by principal component analysis (Table 4). The result if AMMI analysis indicated that $10.01 \%$ of the total variability was justified by genotypes, $75.29 \%$ by environments and $14.71 \%$ by GE interaction. A large contribution of the environment indicated that environments were diverse, with large difference among environmental means causing most of the variation in grain yield. The same result was reported by [8, 26-27]. The result of AMMI analysis also showed that the first principal component axis (IPCA1) accounted for $63.42 \%$ over the interaction SS, IPCA2 and IPCA3 explained $25.16 \%$ and $6.69 \%$ of the GE interaction SS, respectively. The first two IPCA scores were significant at $(\mathrm{P}<0.01 \%)$ and cumulatively accounted for $88.58 \%$ of the total GE interaction. This indicates that the use of AMMI model fit the data well and justifies the use of AMMI2.

Table 4. Analysis of Variance for grain yield of Linseed for the AMMI model.

\begin{tabular}{lllll}
\hline Source of variation & D. F. & Sum of Square & \%SS & M. S. \\
\hline Genotype (G) & 13 & 0.915823 & $10.01^{\mathrm{a}}$ & $0.0704479^{* *}$ \\
Location (L) & 5 & 6.88972 & $75.29^{\mathrm{a}}$ & $1.37794^{* *}$ \\
G X L & 65 & 1.34592 & $14.71^{\mathrm{a}}$ & $0.0207064^{* *}$ \\
IPCA 1 & 17 & 0.853613 & $63.42^{\mathrm{b}}$ & $0.0502125^{* *}$ \\
IPCA 2 & 15 & 0.338712 & $25.16^{\mathrm{b}}$ & $0.0225808^{* *}$ \\
IPCA 3 & 13 & 0.090051 & $6.69^{\mathrm{b}}$ & $0.006927^{* *}$ \\
IPCA 4 & 11 & 0.0549334 & $4.08^{\mathrm{b}}$ & $0.00499394^{* *}$ \\
Residual & 9 & 0.00860686 & & \\
TOTAL & 83 & 9.15146 & & \\
\hline
\end{tabular}

a: from total sum of square percent, b: from GE sum of square percent ** Significant at $1 \%$ probability level

AMMI Stability Value (ASV): ASV is the distance from zero in a two dimensional scattergram of IPCA1 scores against IPCA2 scores. Since the IPCA1 score contributes more to the GE sum of square, it has to be weighted by the proportional difference between IPCA1 and IPCA2 scores to compensate for the relative contribution of IPCA1 and IPCA2 total GE interaction sum squares. The distance from zero is then determined using the theorem of Pythagoras [20]. In general the importance of AMMI model is in reduction of noise even if principal components don't cover much of the GESS [9-10]. 
In ASV method, the genotype with least ASV score is the most stable. AMMI Stability Value (ASV) discriminated genotypes G9, G6, G13, G5 and G11 as the stable genotypes respectively.

Table 5. Regression coefficient, deviation from regression, IPCA scores, ASV and GSI of genotypes.

\begin{tabular}{|c|c|c|c|c|c|c|c|c|c|}
\hline Genotype & Mean Yield (t/ha) & Slop (bi) & MS-DEV & IPCA1 & IPCA2 & IPCA3 & IPCA4 & ASV & GSI \\
\hline G1 & 1.51 & 1.72 & 0.06 & -0.56 & 0.01 & 0.17 & 0.01 & 1.41 & 25 \\
\hline $\mathrm{G} 2$ & 1.53 & 1.19 & 0.02 & 0.11 & -0.41 & -0.11 & 0.19 & 0.50 & 15 \\
\hline G3 & 1.42 & 0.54 & 0.03 & 0.14 & 0.32 & -0.02 & 0.13 & 0.49 & 20 \\
\hline G4 & 1.59 & 0.93 & 0.04 & 0.21 & -0.19 & 0.06 & -0.04 & .57 & 14 \\
\hline G5 & 1.53 & 1.11 & 0.05 & -0.08 & -0.09 & -0.23 & 0.09 & 0.21 & 14 \\
\hline G6 & 1.85 & 0.99 & 0.04 & -0.37 & -0.04 & 0.07 & -0.11 & 0.12 & 3 \\
\hline G7 & 1.55 & 1.25 & 0.01 & -0.30 & 0.04 & -0.28 & -0.22 & 0.76 & 20 \\
\hline G9 & 1.69 & 1.00 & 0.9 & 0.03 & -0.03 & 0.07 & 0.06 & 0.09 & 3 \\
\hline G10 & 1.51 & 0.60 & 0.01 & 0.23 & 0.16 & 0.09 & -0.15 & 0.60 & 22 \\
\hline G11 & 1.64 & 1.07 & 0.01 & -0.14 & 0.10 & -0.05 & 0.20 & 0.37 & 8 \\
\hline G12 & 1.57 & 0.83 & 0.02 & 0.20 & -0.12 & -0.12 & -0.09 & 0.52 & 15 \\
\hline G13 & 1.59 & 1.20 & 0.01 & -0.05 & -0.07 & 0.27 & 0.07 & 0.14 & 8 \\
\hline G14 & 1.44 & 0.36 & 0.04 & 0.20 & 0.44 & -0.05 & 0.05 & 0.67 & 24 \\
\hline
\end{tabular}

N. B. MS-DEV= deviation from regression, IPCA= Interaction Principle Component Analysis axis, ASV= AMMI Stability Value, GSI= Genotype Selection Index

Genotype Selection Index (GSI): As stability per se is not a desirable selection criterion, because the most stable genotypes would not necessarily give the best yield performance [16], hence, simultaneous consideration of grain yield and ASV in single non-parametric index needed. Therefore, the rank of ASV and mean grain yield $\left(\mathrm{RY}_{\mathrm{i}}\right)$ are incorporated in single selection index namely Genotype Selection Index (GSI). The least GSI is considered as the most stable with high grain yield. Thus GSI indicates (Table 4), G6 and G9 have the most stability with high grain yield.

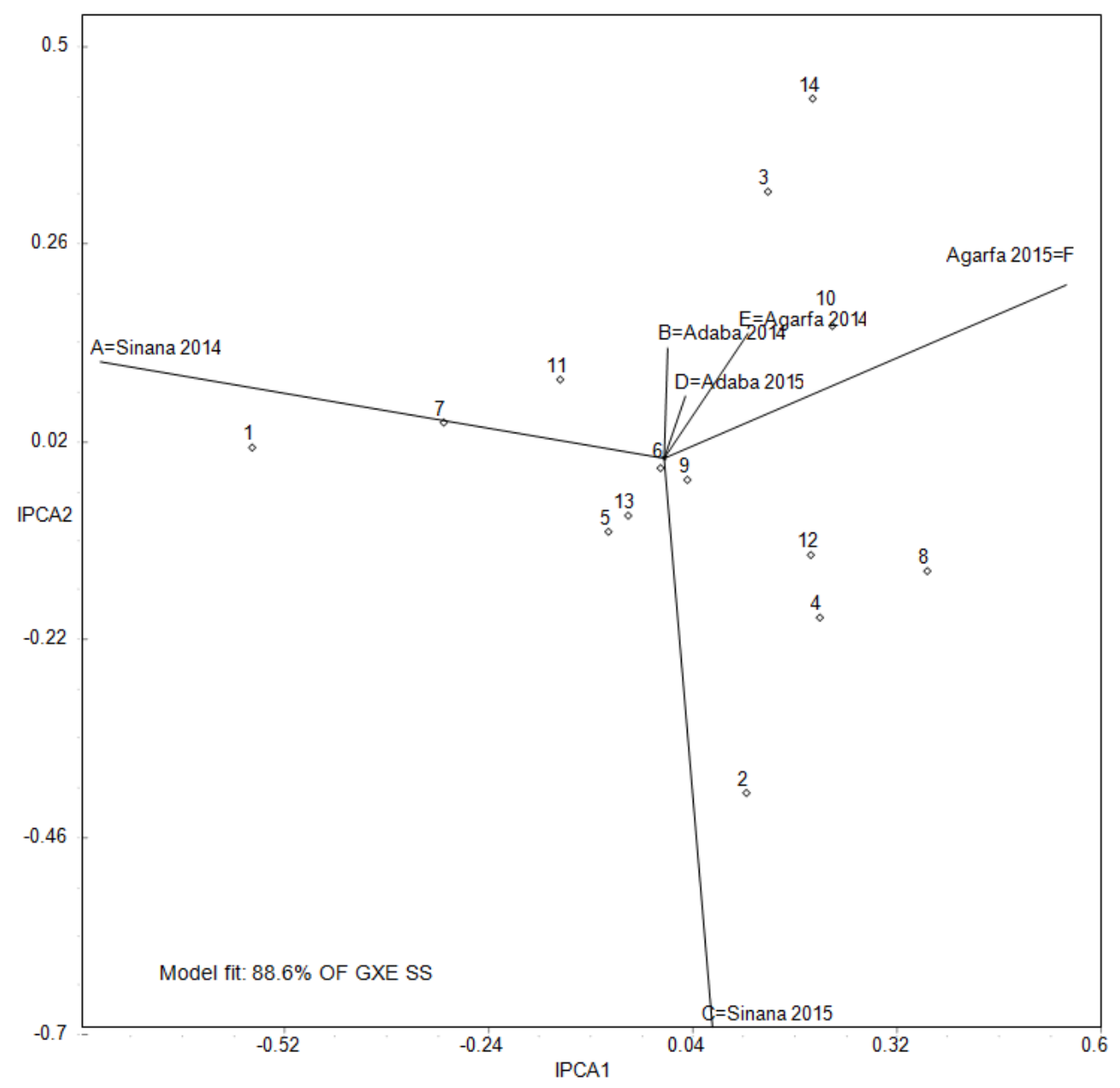

Figure 1. Biplot analysis of GE interaction based on AMM2 model for the first two interactions principal component scores. 
The AMMI2 biplot (Figure 1) explained $88.6 \%$ of the GE interaction, making it a useful test for interaction. It was observed that most of the genotypes and environments were dispersed around the biplot. Genotypes farther from the center of biplot show specific adaptation. [17] In their study revealed that those genotypes which are far from the center of the biplot, have high GE interaction and those genotypes that nearest to the center of biplot, have high stability.

Biplot analysis (Figure 1) displayed that genotypes G1, G2 and G14 and environment $\mathrm{A}, \mathrm{F}$ and $\mathrm{C}$ have greatest effect in the GE interaction. G1 has specific adaptation with environment A, while $\mathrm{G} 2$ has specific adaptation with environment $\mathrm{C}$. genotypes towards the center of biplot have zero interaction, therefore, have general adaptation with different mean grain yield. Genotypes G6, G9, G11, G13 and G5 are located in this category and as the entries G6, G9, G11 and G13 have mean grain yield over the grand mean, therefore they can be considered as stable with high performance. The genotype G1 has specific adaptation with environment A because their angle is less than 90 degree and their GE interaction is positive. Genotypes G2, G4, G8 and G12 have positive interaction with environment $C$, but the length of vector for $\mathrm{G} 2$ is more on the environment $\mathrm{C}$, hence it has specific adaptability with environment C. The G3, G10 and G14 have positive interaction with environment $F$, but G10 is more adapted to it.

\section{Conclusion}

Genotypes-by-environment (GE) interaction has been important and challenging issue among plant breeders, geneticist and agronomists engaged in performance testing. The genotype-environment interaction reduces association between phenotypic and genotypic values and leads bias in the estimates of gene effect and combining ability for various characters sensitive to environmental fluctuation. Such traits are less amenable to selection. Both yield and stability of performance should be considered simultaneously to reduce the effect of GE interaction and to make selection of genotypes more precise and refined.

Based on the stability parameters regression coefficient, deviation from regression and mean grain yield out of the tested G6, G9, G11, and G8 were found to be stable. However, the AMMI Stability Value (ASV) discriminated genotypes G12, G4, G6, G13, and G9 as they stable genotypes respectively. Based on the Genotypes Selection Index (GSI) the most stable genotypes with high grain yield were G6 and G9.

The results of this investigation provide that stability analysis by AMMI model indicated that four principal components were significant and 88.6 percent of the interaction sum of square was related to the first two components. Based on the biplot of AMMI2, ASV and GSI genotypes 6 and genotype 9 revealed the highest stability. Therefore these two genotypes were identified as candidate genotypes to be verified for possible release.

\section{Acknowledgements}

Oromia Agricultural Research Institute for funding, Sinana Agriculture Research Center and pulse and oil crops research case team for full support, data collection and trial management is thankfully acknowledge.

\section{References}

[1] Becker HC and Leon J. 1988. Stability analysis in plant breeding. Plant breeding, 101: 1-23

[2] Crosaa J. 1990. Statistical analysis of multilocation trials. Advance in Agronomy, 44: 55-85

[3] Crossa J, Fox PN, Pfeiffer WH, Rajaram S and Gauch HG. 1991 AMMI adjustment for statistical analysis of an interactional wheat yield trial. Theor. App Gent, 81: 27-37

[4] CSO. 1984. Time Series Data on Area, Production and Yield of Principal Crops by Regions, 1979/80-1983/84. Central Statistics Office, Addis Ababa

[5] Farshadfar E, Farshadfar and M, Sutka J. 2000. Combining ability analysis of drought tolerance in wheat over different water regiems. Acta Agron Hung, 48(4): 353-361

[6] Farshadfar E and Sutka J. 2003. Locating QTLs controlling adaptation in wheat using AMMI model. Cereal Res Commun 31: $249-254$

[7] Farshadfar E, and Sutka E. 2006. Biplot analysis of genotypeenvironment interacting in durum wheat using the AMMI model. Acta Agron. Hung, 54: 459-467

[8] Farshadfar E. 2008. Incorporation of AMMI stability value and grain yield in a single non-parametric index (GSI) in bread wheat. Pak J Biol Sci, 11(4): 1791-1796

[9] Gauch HG. 1992. Statistical anlyis of regional yield trials. AMMI analysis of factorial designs. $1^{\text {st }}$ edn, Elsevier, New York, ISBN: 0-444-89240-0

[10] Gauch HG and Zobel Rw. 1996. AMMI analysis of yield trials. In: Kang MS, Gauch HG (eds) Genotype by environment interaction. CRC press Boca Raton FL

[11] Getinet A, and Negusei A. 1997. Highland Oil Crops: A Three Decade Research Experience in Ethiopia. Research report No. 30. Institute of Agricultural Research, Addis Ababa, Ethiopia.

[12] Hayward MD, Besemard NO and Romagosa L. 1993. Palnt breeding, Principles and Prospects. $1^{\text {st }}$ edn. Chapman and Hall, London U.K. ISBN: 0-412-43390-7

[13] Hussein MA, Bjornstad A and Aastveit AH. 2000. SASG3 ESTAB: A SAS program for computing genotype 3 environment stability statistics. Agron J, 92: 454-459

[14] Lin CS, Binns Mr and Lefkovitch LP. 1986. Stability analysis: where do we stand? Crop Sci, 26: 894-900

[15] Lin CS and Binns MR. 1994. Concepts and methods for analyzing regional trial data for cultivar and location selection. Plan breed Rev, 12: 271-297 
[16] Mohamaddi R and Haghparast R. 2007 Biplot analysis of multi-environment trials for identification of winter wheat mega-environment in Iran. World J. Agri Sci, 3: 475-480

[17] Mohammadi R and Amri A. 2008. Comparsion of parametric and non-parametric methods for selecting stable and adapted durum wheat genotypes in variable environments. Euphytica, 159: 419-432

[18] Mohammadi R, Mozaffar Roostaei M, Yousef A, Mostafa A and Amri A. 2010. Relationship of phenotypic stability measures for genotypes of three cereal crops. Can J Plant Sci, 90:819-830

[19] Pourdad SS and Mohammadi R. 2008. Use of stability parameters for comparing safflower genotypes in multienvironment trials. Asian J. Plant Sc, i 7: 100-104

[20] Purchase JL, Hatting H and Vandenventer CS. 2000. Genotype $\mathrm{x}$ environment interaction of winter wheat in south Africa: II. Stability analysis of yield performance. South Afr J Plant Soil, 17: 101-107

[21] Solomon A, Nigussie M, and Habtamu Z. 2008. Genotypeenvironment interaction and stability analysis for grain yield of maize (Zea mays L.) in Ethiopia. Asian J. Plant Sci, 7: 163169
[22] Tarakanovas P and Rusgas V. 2006. Additive main effect and multiplicative interaction analysis of grain yield of wheat varieties in Lithuania. Agron Res, 4: 91-98

[23] Wade LJ, Sarkarung S, Melran CG, Guhey A and Quader B. 1995. Genotype by environment interaction and selection method for identifying improved rainfed lowland rice genotypes. $1^{\text {st }}$ edn, International Rice Research Institute pp: $883-900$

[24] Yaghotipoor A and Farshadfar E. 2007. Non-parametric estimation and component analysis of phenotypic stability in chickpea (Cicer arietinum L.) Pak J Biol Sci, 10: 2646-2649

[25] Vavilov NI. 1926. Studies on the origin of cultivated plants. Bull. Bet. and Pl. breed, 16: 139-248

[26] Jacobsz MJ, Merwe WJCV and Westhuizen MMV 2015. Additive Main Effects and Multiplicative Interaction Analysis of European Linseed (Linum Ustatissimum L.) Cultivars under South African Conditions. Adv Plants Agric Res 2(3): 00049. DOI: 10.15406/apar.2015.02.00049

[27] Marisol B, Susana F, Rosemarie W, Felicitas H and Burton J. 2010. Adaptation and genotype $\mathrm{x}$ environment interaction of flaxseed (linum usitatissimum 1.) genotypes in south central chile. Chilean J. Agri. Res. 70(3): 345-356 